\title{
Factors associated with recent HIV testing among high-risk men who have sex with men: a cross-sectional study in Cambodia
}

\author{
Siyan $\mathrm{Yi}^{1}{ }^{12^{*}}$, Sovannary Tuot ${ }^{1}$, Pheak Chhoun ${ }^{1}$, Carinne Brody ${ }^{2}$, Khuondyla Pal ${ }^{1}$ and Sopheap Oum ${ }^{1}$
}

\begin{abstract}
Background: Despite remarkable success in the fight against HIV, HIV prevalence in many countries remains high among key populations including men who have sex with men (MSM), and HIV testing rates is relatively low among this hard-to-reach population. This cross-sectional study explores factors associated with recent HIV testing among MSM in Cambodia.
\end{abstract}

Methods: This study was conducted in 2014 and included 384 MSM randomly selected from two provinces of Battembang and Siem Reap, using a two-stage cluster sampling method. A structured questionnaire was used for face-to-face interviews to collect data on socio-demographic characteristics, HIV testing history, sexual behaviors, HIV testing attitudes, and HIV knowledge. Multivariate logistic regression analysis was performed to identify factors independently associated with recent HIV testing.

Results: Mean age of the participants was 23.4 (SD = 5.2). Of total, $83.6 \%$ had been tested for HIV at least once in their lifetime, and $65.1 \%$ had been tested for HIV in the past six months. After controlling for other covariates, MSM who had been tested for HIV in the past six months were significantly more likely to regard themselves as female (AOR $=2.29,95 \%$ $\mathrm{Cl}=1.06-5.37$ ), have received some form of HIV education in the past six months ( $\mathrm{AOR}=3.97,95 \% \mathrm{Cl}=1.91-8.26$ ), perceive that they were at higher HIV risk compared to the general population ( $A O R=2.48,95 \% \mathrm{Cl}=1.14-4.86$ ), have been diagnosed with an $\mathrm{STI}$ in the past six months $(\mathrm{AOR}=3.19,95 \% \mathrm{Cl}=1.02-9.24)$, report using a condom at last sexual intercourse with a man or woman ( $\mathrm{AOR}=2.24,95 \% \mathrm{Cl}=1.06-3.13)$, and report using a condom at last sexual intercourse with a boyfriend $(\mathrm{AOR}=2.17,95 \% \mathrm{Cl}=1.04-5.31)$.

Conclusions: This study highlights the common practices of risky sexual behaviors and relatively low rate of recent HIV testing among MSM in Cambodia. HIV education and social marketing should be expanded and tailored for MSM, specifically addressing the risk of unprotected anal intercourse and the importance of regular HIV testing for early enrolment in the care and treatment cascade.

Keywords: Men who have sex with men, HIV testing, Risky sexual behaviors, Condom use, Cross-sectional study, Cambodia

\footnotetext{
* Correspondence: siyan@doctor.com

${ }^{1}$ Research Center, KHANA, No. 33, Street 71, P.O Box 2311-PP3, Phnom Penh, Cambodia

${ }^{2}$ Center for Global Health Research, Public Health Program, Touro University California, 1310 Club Drive, Vallejo, CA 94594, USA
} 


\section{Background}

Cambodia has been recognized for successful HIV prevention and control efforts that have contributed to a decline in HIV prevalence in the general population aged 15 to 49 from approximately $2 \%$ in late 1990's to $0.6 \%$ in $2013[1,2]$. The country has also achieved the universal access target for antiretroviral therapy (ART), with over $90 \%$ of people living with HIV (PLHIV) in need for ART receiving the treatment [1]. Moreover, annual AIDS-related deaths have been reduced by twothirds over the past 10 years [2]. As a result, Cambodia received a Millennium Development Goal award from the United Nations in 2010 [3]. Despite these remarkable achievements, Cambodia is facing emerging challenges in the concentrated HIV epidemic in key populations. HIV prevalence remains very high among female entertainment workers (FEWs), injecting drug users (IDUs), men who have sex with men (MSM), and transgender people (TG) $[2,4,5]$.

The concerns about resurgence of HIV infection among MSM first started in the Western world [6-8], and emerged later on in Latin America, Africa, and Asia [9-12]. The substantial risk for HIV infection among MSM has been reported in different socio-cultural contexts throughout the world [13-17]. Because of the hidden and stigmatized nature of MSM, there are data gaps and challenges to research, surveillance, and epidemiological characterization in MSM populations [18]. HIV prevention and care among these populations remains challenging. Recent studies have consistently reported that HIV testing rates remain low among MSM in many countries [19-26]. In Cambodia, the BROS Khmer Study conducted in 2010 found that $60 \%$ of the study sample reported having been tested for HIV in their lifetime, and among these men, $64 \%$ reported having had an HIV test in the past 12 months [5]. According to the most recent Behavioral Sentinel Surveillance (BSS 2013), approximately $87 \%$ of MSM had been tested for HIV in the past 12 months, and $70 \%$ had been tested for HIV in the past three months [27]. Among MSM in the BROS Khmer Study, the prevalence of HIV and sexually transmitted infections (STIs) were $2.2 \%$ and $52 \%$, respectively [5].

Regular HIV testing, particularly in key populations with high HIV prevalence, plays a very important role in reducing new HIV infections through early HIV detection, and it is the first step in engaging infected people in the care and treatment cascade [24]. Early detection not only reduces the chance of HIV transmission but also enables timely treatment to reduce HIV-related mortality and morbidity [28]. Moreover, a recent Cochrane review of studies in many developing countries found that HIV voluntary confidential counseling and testing (VCCT) is effective in increasing case detection and reducing risky sexual behaviors [29]. Promoting HIV testing is thus very important in
HIV prevention, care, and support for at-risk MSM. The World Health Organization (WHO) recommends that MSM with high-risk behaviors should receive HIV testing every six to 12 months [30], while the U.S Center for Disease Control and Prevention (CDC) recommends sexually active MSM to get tested for HIV every three to six months [31]. These goals are reached only if barriers to HIV testing are identified, and effective strategies to overcome these barriers are put in place.

Several factors associated with HIV testing among MSM have been identified in different settings. These factors include characteristics such as age, education, mobility, sexual behaviors, perception of HIV risk, perceived stigma and discrimination towards MSM in communities and health facilities, HIV testing attitudes, perceived necessity of HIV test, and fears of positive results [20-22, 24-26, 32, 33]. However, several findings in these existing studies were not consistent. For examples, studies among MSM in Chongqing, China [22, 26] found that HIV testing was associated with the report of protected sexual intercourse, while another study in Beijing, China found that HIV testing was associated with the report of unprotected sexual intercourse [33]. Similarly, the relationship between HIV testing and perceived low HIV risk was found in another study in mainland China [26] and Thailand [25], while a study in Hong Kong found that HIV testing was associated with greater perception of chance of having sexual intercourse with HIV-infected people in the next six months [21]. Other studies also reported that perception of low HIV risk was also one of the reasons for not having been tested for HIV [23, 34].

The discrepancy in the findings in different populations may indicate the effects of socio-cultural aspects of MSM on the relationships between HIV testing and related factors and merits further investigations. Moreover, most of the available studies in the literature have examined factors associated with history of lifetime HIV testing [24-26, 34], HIV testing in the past 12 months $[35,36]$, or intention to take up HIV testing [20, 21]. Findings from these studies are definitely important; however, it is more critical to understand factors related to more recent HIV testing history. The Cambodia's national guideline recommends HIV testing at least once in six months for sexually active MSM to identify new HIV infections and prevent ongoing transmission [1]. To address this literature gap, we conducted this cross-sectional study to explore factors associated with recent HIV testing (in the past six months) among MSM in Cambodia.

\section{Methods}

\section{Study sites and population}

Data were collected in April and May 2014 as part of an impact evaluation of the Sustainable Action against HIV and AIDS in Communities (SAHACOM) 
project. The details of the main study have been published elsewhere [37-40].

In brief, data were collected from 394 MSM randomly selected from venues and hotspots identified by community-based workers in two provinces of Battembang and Siem Reap provinces. A two-stage cluster sampling method was used to select the study sample with communes in each province as the smallest unit for the sampling. We included only communes with at least $20 \mathrm{MSM}$; and other conditions, such as convenience and accessibility, were also considered to justify whether to include or exclude a venue or hotspot. We then used the probability proportional-tosize sampling to select the required number of MSM from each commune. Inclusion criteria for participation in this study were: (1) age of 18 years or older; (2) self-reported as an MSM; (3) having had sexual intercourse experience; (4) being able to provide consent to participate in the study; and (5) being able to present themselves on the day of the data collection. In data cleaning, we found ten respondents $(2.5 \%)$ who did not have sexual experience, and they were excluded from the analyses.

\section{Questionnaire development and training}

A structured questionnaire was initially developed in English and translated into Khmer, the national language of Cambodia, and it was then back-translated into English by another translator. A pilot study was conducted with a sample of 10 MSM in Phnom Penh to ensure that the wording and contents were culturally suitable, acceptable, and clearly understandable for the participants. Necessary modifications were made after receiving comments from experts working on HIV in key populations in Cambodia as well as feedbacks from the pilot study.

A three-day training was conducted for all research team members on data collection methods and tool pretesting and reflection. The contents of training included privacy assurance, confidentiality, interview techniques, and reviews of the study protocol and questionnaire. Research team members were also equipped with quality control skills such as rechecking and reviewing the questionnaires after administration as well as resolving issues that might arise during the fieldwork. We encouraged data collection team leaders to perform regular review sessions with interviewers to review progress and communicate any issues occurring during the data collection.

\section{Variables and measurements}

We adapted standardized tools from a previous study in the same population [41], the most recent Cambodia Demographic and Health Survey [42], as well as from other studies in Cambodia [43, 44] to measure socio- economic characteristics, perceived HIV risk, sexual behaviors, history of STIs, history of HIV testing, health care seeking behaviors, and HIV education.

For socioeconomic characteristics, we collected information on age, marital status, years of formal education completed, main occupation, average monthly income, living situations, and personal perception about sexual identity. To assess history of HIV testing, a yes/no question was used, "In the past six months, have you been tested for HIV?" Condom use was measured by using yes/no questions asking whether they used a condom at last sexual intercourse with different types of partners such as regular female partners, regular male partners, female sex workers, male sex workers, female clients, and male clients. Yes/no questions were also used to collect information on several other sexual behaviors in the past three months with the above-mentioned partners. We also collected data on HIV education they received in the past six months, STI symptoms in the past three months, and illicit drug use in the past six months.

HIV testing attitudes were measured using five items adapted from a previous study on HIV testing and testing attitudes [45]. Two items reflected positive outcomes from testing, two assessed adverse outcomes, and one item reflected HIV testing avoidance. The participants responded to each statement dichotomously, as either "agree" or "disagree." To measure HIV knowledge, we used a 12-item scale that reflected information about HIV transmission, condom use, and HIV knowledge [46]. The items were answered as 'yes', 'no', or 'don't know' with 'don't know' responses regarded as incorrect.

\section{Ethical considerations}

This study was approved by the National Ethics Committee for Health Research, Ministry of Health, Cambodia (Ref no. 082NECHR). Participants were made clear that participation in this study was voluntary, and they could refuse or discontinue their participation at any time for any reason. We obtained a written informed consent from each participant after a detailed description of the study was provided. To ensure the confidentiality, no personal identifiers were collected, and code numbers were used. Privacy of the respondents was protected by conducting the interviews at a private place.

\section{Data analyses}

EpiData version 3 (Odense, Denmark) was used for double data entry, and SPSS version 22 (IBM Corporation, New York, USA) was used for all statistical analyses. Chi-square test or Fisher's exact test was used as appropriate for categorical variables, and Student's $t$-test was used for continuous variables to compare sociodemographic characteristics, sexual behaviors, HIV testing attitudes, and HIV knowledge among MSM 
who had and who had not been tested for HIV in the past six months. A multivariate logistic regression analysis was performed to examine factors independently associated with recent HIV testing, controlling for potential confounders. Variables significantly associated with HIV testing in bivariate analyses at a level of $p<0.2$ were simultaneously included in the model. In the model, variables with a $p$-value $>0.05$ were then removed for model fitting, and the steps were repeated until all $p$-values of the remaining variables were $<0.05$ in the final model. Multicollinearity was detected between condom use and lubricant use in last anal intercourse with a boyfriend; the variable for lubricant use was thus excluded from the model. Adjusted odds ratio (AOR) were calculated and presented with $95 \%$ confidence intervals $(\mathrm{CI})$ and $p$-values.

\section{Results}

\section{History of HIV testing}

This study included 384 MSM with a mean age of 23.4 $(\mathrm{SD}=5.2)$. On average, $83.6 \%$ of the participants reported having been tested for HIV at least once in their lifetime, and $65.1 \%$ had been tested in the past six months. They received their most recent HIV testing at a VCCT site (45.9\%), through community- or peerinitiated HIV testing (43.3\%), or at a private facility (10.8 \%). Most of them (65.2\%) were referred by peer educators, outreach workers, or other NGO staff for HIV testing; $19.9 \%$ were self-referred; and $10.2 \%$ were referred by friends or colleagues. The majority received the result $(98.2 \%)$ and counselling $(95.7 \%)$ for the most recent testing. When asked about the reasons for not getting tested, more than half (56.3\%) of participants who had not been tested for HIV in the past six months responded that they did not think they were at risk for HIV, and $15.0 \%$ raised their fear of positive result as the main reason for not getting tested.

\section{Comparisons of socio-demographic characteristics}

Table 1 shows comparisons of socio-demographic characteristics of MSM who had and who had not been tested for HIV in the past six months. More than half $(56.8 \%)$ of the respondents regarded themselves as male, and $21.1 \%$ and $22.1 \%$ regarded themselves as female and both genders, respectively. The majority (90.1\%) were never married with mean years of formal education completed of $9.5(\mathrm{SD}=3.2)$. The most common job was self-employed (29.6\%), followed by students $(26.6 \%)$ and other jobs such as working as a hairdresser, a barber, or in a beauty salon shop $(23.4 \%)$. Their average monthly income was $\$ 205(\mathrm{SD}=\$ 613)$. More than two-thirds (71.4\%) lived with their parents, and $84.9 \%$ had received some form of HIV education in the past six months. When asked to compare level of their HIV risk, 35.4\% perceived themselves as having higher risk; $18.0 \%$ perceived themselves as having the same risk, and $46.6 \%$ perceived themselves as having lower risk compared to the general population.

Compared to participants who had not been tested for HIV in the past six months, those who had been tested were significantly more likely to regard themselves as female $(27.2 \%$ vs. $9.7 \%, p<0.001)$ and less likely to live with their parents $(69.1 \%$ vs. $75.6 \%, p=0.007)$. They were also significantly more likely to have received some form of HIV education in the past six months $(91.6 \%$ vs. $72.2 \%, p<0.001)$ and to perceive themselves as having higher HIV risk compared to the general population $(40.8 \%$ vs. $25.4 \%, p=0.007)$.

\section{Comparisons of sexual behaviors}

Comparisons of sexual behaviors among participants who had and who had not been tested for HIV in the past six months are shown in Table 2. Mean number of sex partners in the past three months was significantly higher among participants who had been tested for HIV $(3.2 \pm 3.8$ vs. $4.5 \pm 6.2, p=0.02)$. Participants who had been tested were significantly more likely to report using a condom at last sexual intercourse with a man or woman $(87.4 \%$ vs. $74.2 \%, p=0.001)$ and at last sexual intercourse with a girlfriend (89.0 \% vs. $71.1 \%, p=0.01)$. They were significantly less likely to have a girlfriend (44.4 \% vs. $60.4 \%, p=0.003$ ), but more likely to have a boyfriend $(69.2 \%$ vs. $49.3 \%, p<0.001)$ in the past three months. Participants who had been tested for HIV were also significantly more likely to report using a condom (95.4 \% vs. 82.4 \%, $p=0.003)$ and lubricant $(85.4 \%$ vs. $62.0 \%, p<0.001)$ at last anal intercourse with a boyfriend, and less likely to have sexual intercourse with female sex workers in the past three months $(11.6 \%$ vs. $20.1 \%, p=0.03)$. They were also significantly more likely to have been diagnosed with an STI in the past six months ( $9.6 \%$ vs. $2.3 \%, p=0.006$ ).

\section{HIV testing attitudes and knowledge}

In general, MSM in this study expressed positive attitudes towards HIV testing. For example, $95.6 \%$ agreed that getting tested for HIV helps people feel better, and only $30.7 \%$ supported the statement that, "I would rather not know if I have HIV." No significant difference was found in the comparisons of HIV testing attitudes among participants who had and who had not been tested for HIV in the past six months. Similarly, the majority of MSM in this study responded correctly to most of HIV knowledge questions. A large knowledge gap was noted in a question regarding if a person must have many different partners to get HIV. No significant difference was found in comparisons of HIV knowledge among participants who had and who had not been tested for HIV in the past six months. 
Table 1 Comparisons of socio-demographic characteristics of MSM who had and who had not been tested for HIV

\begin{tabular}{|c|c|c|c|c|}
\hline \multirow[t]{2}{*}{ Socio-economic characteristics } & \multirow[t]{2}{*}{ Total $(n=384)$} & \multicolumn{3}{|c|}{ HIV testing in the past 6 months } \\
\hline & & No $(n=134)$ & Yes $(n=250)$ & $p$-value \\
\hline Mean age (in year) & $23.4 \pm 5.2$ & $23.4 \pm 4.4$ & $24.1 \pm 5.6$ & 0.18 \\
\hline \multicolumn{2}{|l|}{ Perceived sexual identity } & & & $<0.001$ \\
\hline Male & $218(56.8)$ & $95(70.9)$ & $123(49.2)$ & \\
\hline Female & $81(21.1)$ & $13(9.7)$ & $68(27.2)$ & \\
\hline Both & $85(22.1)$ & $26(19.4)$ & 59 (23.6) & \\
\hline \multicolumn{2}{|l|}{ Marital Status } & & & 0.70 \\
\hline Never married & $345(90.1)$ & 120 (89.6) & $225(90.4)$ & \\
\hline Married & $30(7.8)$ & $12(9.0)$ & $18(7.2)$ & \\
\hline Divorced, separated, or widowed & $8(2.1)$ & $2(1.5)$ & $6(2.4)$ & \\
\hline Years of formal education completed & $9.5 \pm 3.2$ & $9.4 \pm 3.5$ & $9.6 \pm 3.1$ & 0.53 \\
\hline \multicolumn{2}{|l|}{ Main occupations } & & & 0.24 \\
\hline Unemployed & $16(4.3)$ & $7(5.3)$ & $9(3.8)$ & \\
\hline Students & $98(26.6)$ & $38(28.8)$ & $60(25.4)$ & \\
\hline Farmer/laborer & $59(16.0)$ & $24(18.2)$ & $35(14.8)$ & \\
\hline Self-employed & 109 (29.6) & $41(31.1)$ & $68(28.8)$ & \\
\hline Other & $86(23.4)$ & $22(16.7)$ & $64(27.1)$ & \\
\hline Mean monthly income (in US\$) & $205 \pm 613$ & $211 \pm 738$ & $201 \pm 536$ & 0.89 \\
\hline \multicolumn{2}{|l|}{ Currently living with: } & & & 0.007 \\
\hline Parents & $269(71.4)$ & $99(75.6)$ & $170(69.1)$ & \\
\hline Relatives/siblings & $37(9.8)$ & $3(2.3)$ & $34(13.8)$ & \\
\hline Spouse/sexual partner & $32(8.5)$ & $15(11.5)$ & $17(6.9)$ & \\
\hline Friends/colleagues & $25(6.6)$ & $9(6.9)$ & $16(6.5)$ & \\
\hline Other & $14(3.7)$ & $5(3.8)$ & $9(3.7)$ & \\
\hline Mean years living in current city & $19.6 \pm 8.8$ & $18.7 \pm 9.0$ & $20.0 \pm 8.6$ & 0.15 \\
\hline Received HIV education (past 6 months) & $325(84.9)$ & $96(72.2)$ & $229(91.6)$ & $<0.001$ \\
\hline \multicolumn{5}{|c|}{ Sources of HIV education received in the past 6 months } \\
\hline Media (TV/radio/newspaper) & $188(57.7)$ & $64(66.0)$ & $124(54.1)$ & 0.04 \\
\hline Poster/billboard/booklet & $85(26.1)$ & $25(25.8)$ & $60(26.2)$ & 0.94 \\
\hline Peer educator/outreach workers & $295(90.5)$ & $85(87.6)$ & $210(91.7)$ & 0.25 \\
\hline Counseling at VCCT & $16(4.9)$ & $5(5.2)$ & $11(4.8)$ & 0.89 \\
\hline Public health facilities & $33(10.1)$ & $7(7.2)$ & $26(11.4)$ & 0.26 \\
\hline Other & $33(10.1)$ & $10(10.3)$ & $23(10.0)$ & 0.94 \\
\hline \multicolumn{2}{|c|}{ Perception of HIV risk compared to the general population } & & & 0.007 \\
\hline Higher & $136(35.4)$ & $34(25.4)$ & $102(40.8)$ & \\
\hline Same & $69(18.0)$ & $31(23.1)$ & $38(15.2)$ & \\
\hline Lower & 179 (46.6) & 69 (51.5) & $110(44.0)$ & \\
\hline
\end{tabular}

MSM men who have sex with men, TV television, VCCT voluntary confidential counseling and testing

Values are number (\%) for categorical variables and mean \pm SD for continuous variables

${ }^{*}$ Chi-square test or Fisher's exact test was used for categorical variables and Student's $t$-test was used for continuous variables

\section{Factors associated with recent HIV testing}

Table 3 shows factors which remained significantly associated with recent HIV testing in the multivariate logistic regression model. After controlling for other covariates, participants who had been tested for HIV in the past six months were significantly more likely to regard themselves as female $(\mathrm{AOR}=2.29,95 \% \mathrm{CI}=1.06-5.37)$, have received some form of $\mathrm{HIV}$ education in the past six months $(\mathrm{AOR}=3.97,95 \% \mathrm{CI}=1.91-8.26)$, perceive that they were at higher HIV risk compared to the general 
Table 2 Comparisons of sexual behaviors among MSM who had and who had not been tested for HIV

\begin{tabular}{|c|c|c|c|c|}
\hline \multirow[t]{2}{*}{ Sexual behaviors in the past 3 months } & \multirow[t]{2}{*}{ Total $(n=384)$} & \multicolumn{3}{|c|}{ HIV testing in the past 6 months } \\
\hline & & No $(n=134)$ & Yes $(n=250)$ & $p$-value ${ }^{*}$ \\
\hline Mean number of sex partners & $4.0 \pm 5.5$ & $3.2 \pm 3.8$ & $4.5 \pm 6.2$ & 0.02 \\
\hline Condom use at last sexual intercourse & $313(82.8)$ & $98(74.2)$ & $215(87.4)$ & 0.001 \\
\hline Had a girlfriend & $192(50.0)$ & $81(60.4)$ & $111(44.4)$ & 0.003 \\
\hline Had sexual intercourse with a girlfriend & $118(61.5)$ & $45(55.6)$ & $73(65.8)$ & 0.15 \\
\hline Mean number of girlfriends you had sex with & $1.7 \pm 1.1$ & $1.8 \pm 1.3$ & $1.7 \pm 1.0$ & 0.63 \\
\hline Condom use at last sex with a girlfriend & $97(82.2)$ & $32(71.1)$ & $65(89.0)$ & 0.01 \\
\hline Had a boyfriend & $239(62.2)$ & $66(49.3)$ & $173(69.2)$ & $<0.001$ \\
\hline Had sexual intercourse with boyfriends & $205(86.9)$ & $53(81.5)$ & $152(88.9)$ & 0.14 \\
\hline Mean number of boyfriends you had sex with & $2.4 \pm 3.9$ & $1.8 \pm 2.0$ & $2.6 \pm 4.3$ & 0.20 \\
\hline Condom use in last anal sex with a boyfriend & $186(92.1)$ & $42(82.4)$ & $144(95.4)$ & 0.003 \\
\hline Lubricant use in last anal sex with a boyfriend & $160(79.6)$ & $31(62.0)$ & $129(85.4)$ & $<0.001$ \\
\hline Had sexual intercourse with female sex workers & $56(14.6)$ & $27(20.1)$ & $29(11.6)$ & 0.03 \\
\hline Condom use in last sex with female sex workers & $52(92.9)$ & $24(88.9)$ & $28(96.6)$ & 0.34 \\
\hline Had sexual intercourse with male sex workers & $38(9.9)$ & $13(9.8)$ & $25(10.0)$ & 0.94 \\
\hline Condom use in last sex with male sex workers & $35(94.6)$ & $11(91.7)$ & $24(96.0)$ & 0.59 \\
\hline Sold sex to women & $34(8.9)$ & $14(10.4)$ & $20(8.0)$ & 0.42 \\
\hline Condom use in last time selling sex to women & $32(97.0)$ & $13(92.9)$ & $19(100)$ & 0.42 \\
\hline Sold sex to men & $67(17.4)$ & $18(13.4)$ & 49 (19.6) & 0.13 \\
\hline Condom use in last time selling sex to men & $63(94.0)$ & $16(88.9)$ & $47(95.9)$ & 0.29 \\
\hline Always used lubricant when selling sex to men & $41(64.1)$ & $9(50.0)$ & $32(69.6)$ & 0.14 \\
\hline Diagnosed with an STI in past 6 months & $27(7.1)$ & $3(2.3)$ & $24(9.6)$ & 0.006 \\
\hline
\end{tabular}

MSM men who have sex with men

Values are number (\%) for categorical variables and mean \pm SD for continuous variables

${ }^{*}$ Chi-square test or Fisher's exact test was used for categorical variables and Student's $t$-test was used for continuous variables

population $(\mathrm{AOR}=2.48,95 \% \mathrm{CI}=1.14-4.86)$, have been diagnosed with an STI in the past six months $(\mathrm{AOR}=3.19,95 \% \mathrm{CI}=1.02-9.24)$, report using a condom at last sexual intercourse with a man or woman ( $\mathrm{AOR}=2.24,95 \% \mathrm{CI}=1.06-3.13)$, and report using a condom at last anal intercourse with a boyfriend $(\mathrm{AOR}=2.17,95 \% \mathrm{CI}=1.04-5.31)$.

\section{Discussion}

The majority of MSM in this study had been tested for HIV at least once in their lifetime, and about two-thirds had been tested in the past six months. These rates are higher than the rates reported in 2010 [5] and similar to the results from the national BSS 2013 [27]; however, it remains far below the goal recommended by the WHO [30] and CDC [31]. In Cambodia, HIV testing and counselling services have been widely offered free of charge at VCCT centers and in communities through an extensive network of community support volunteers and peer outreach workers who work closely with key populations including MSM.
We found that MSM who had been tested for HIV in the past six months were more likely to have received some form of HIV education in the past six months. HIV education is a core component of communitybased intervention programs in Cambodia that might be effective in reducing risky sexual behaviors and increasing access to HIV prevention and care services through partnership with MSM networks [2]. Collaboration between community support volunteers and peer outreach workers at MSM hotspots play a very important role in improving access to HIV education as well as HIV and STI screening for this hard-to-reach population. Future HIV prevention and care programs for MSM should emphasize the importance and advantages of knowing one's HIV status. Our data showed that peer educators and outreach workers were the main source of HIV education for MSM, indicating that community-based approaches that have been employed in intervention programs, such as the SAHACOM project, are crucial in reaching MSM with education and focused prevention [47]. To maximize the effectiveness of the education, the contents of the materials used for the education should be regularly reviewed and 
Table 3 Factors associated with recent HIV testing among MSM in a multiple logistic regression model

\begin{tabular}{|c|c|c|}
\hline \multirow[t]{2}{*}{ Variables in the model ${ }^{*}$} & \multicolumn{2}{|c|}{ HIV testing in the past 6 months } \\
\hline & AOR $(95 \% \mathrm{Cl})$ & $p$-value \\
\hline \multicolumn{3}{|l|}{ Gender identity } \\
\hline Male & Reference & \\
\hline Female & $2.29(1.06-5.37)$ & 0.04 \\
\hline Both & $1.13(0.59-2.13)$ & 0.71 \\
\hline \multicolumn{3}{|c|}{ Received some form of HIV education in the past 6 months } \\
\hline No & Reference & \\
\hline Yes & $3.97(1.91-8.26)$ & $<0.001$ \\
\hline \multicolumn{3}{|c|}{ Perception of HIV risk compared to the general population } \\
\hline Same & Reference & \\
\hline Higher & $2.48(1.14-4.86)$ & 0.02 \\
\hline Lower & $1.16(0.53-2.35)$ & 0.56 \\
\hline \multicolumn{3}{|c|}{ Diagnosed with an STI in the past 6 months } \\
\hline No & Reference & \\
\hline Yes & $3.19(1.02-9.24)$ & 0.04 \\
\hline \multicolumn{3}{|c|}{ Condom use in last sexual intercourse with a man or a woman } \\
\hline No & Reference & \\
\hline Yes & $2.24(1.06-3.13)$ & 0.03 \\
\hline \multicolumn{3}{|c|}{ Condom use in last anal intercourse with a boyfriend } \\
\hline No & Reference & \\
\hline Yes & $2.17(1.04-5.31)$ & 0.04 \\
\hline
\end{tabular}

$A O R$ adjusted odds ratio, $C l$ confidence interval; MSM men who have sex with men

"Variables in the table were the ones that remained statistically significant after several steps of model fitting

updated with active involvement from community workers and stakeholders.

Risk perception seems to play a key role in MSM's decision whether to get tested for HIV. MSM who perceived themselves at higher HIV risk compared to the general population were more likely to get tested for HIV in the past six months compared to those who thought they were at the same risk. Moreover, when asked about the reasons for not getting tested, more than half responded that they did not think they were at risk for HIV. These findings do not support previous studies in which perception of high HIV risk may prohibit MSM from getting tested $[25,26,33,36,48]$. However, they are in line with a study among MSM in Hong Kong, which reported that MSM who perceived higher chance of having sexual intercourse with HIV-infected people in the next six months were more likely to report having been tested for HIV [21]. This finding indicates a need for greater awareness of HIV risk among MSM in Cambodia as almost $60 \%$ of the respondents perceived the level of their HIV risk to be the same or lower than that in the general population, despite their active involvement in risky sexual behaviors. On the other hand, it may highlight stronger supports in care and treatment services for HIV-infected people in some countries such as Cambodia and Hong Kong that may encourage high-risk MSM to get tested.

In this study, MSM who had been tested for HIV in the past six months were more likely to report using a condom at last sexual intercourse with male or female partners and at last anal intercourse with a boyfriend. A previous study in New Zealand reported that HIV testing was significantly associated with consistent condom use during anal intercourse with casual partners, but condom use with regular partners was not a factor [35]. Perception of high likelihood of having unprotected anal intercourse was associated with lower intention to take up VCCT services among MSM in Hong Kong [21]. This finding could be interpreted in another way that MSM who were involved in unprotected sex may not want to get tested because of fear of positive result. Fear of testing positive is closely related to stigma and discrimination $[49,50]$, and was the second most common reason for not getting tested among MSM in our study. Fear of consequences of a positive result is common among MSM who are involved in risky sexual behaviors and has been found to be the main reason for not getting tested [19, 23, 25, 26]. However, in contrast, many other studies found that MSM with more experience of risky sexual behaviors were more likely to undergo HIV testing because of their awareness of the risk involvement, and HIV testing is used to confirm or rule out the possibility of the transmission [22, 33].

HIV testing attitudes and knowledge were generally good but were not associated with recent HIV testing among MSM in this study. These findings do not necessarily indicate that HIV education is not important for MSM in Cambodia but may suggest the need for development of HIV education materials specifically designed for MSM. Previous studies have highlighted the importance of inclusion of specific knowledge items for MSM such as the information that unprotected anal intercourse exposes MSM to higher risk of HIV and STI transmission than vaginal intercourse, as well as the importance of lubricant use in anal intercourse [51, 52]. Such knowledge may change their HIV risk perception, and in turn lead to the increased uptake of HIV testing among MSM.

The major limitation of this study concerns the representativeness of the study samples as we included only MSM in two provinces where the SAHACOM, a comprehensive community-based HIV project, has been implemented for MSM. The levels of HIV risk and outcomes reported in this study may therefore represent a more optimistic view than in other areas of Cambodia. Future studies should include a wider range of MSM subpopulations; particularly those who are not reached by the intervention programs. Second, 
data used for this analysis were collected as part of an impact evaluation of the SAHACOM project. Thus the sampling scheme was not necessarily designed for this cross-sectional analysis. Third, the self-reported measures may lead to inherent biases potential for both underreporting and over-reporting. However, measures were taken to create conditions that encouraged valid responses from the respondents; their responses were confidential, and interviews were conducted in a private place by well-trained interviewers. Lastly, directions of causality could not be established due to the cross-sectional nature of the study. For instance, it remains unclear whether some factors, such as HIV education, contributed to recent HIV testing, or conversely, HIV testers were more likely to receive HIV education when they received HIV testing. Longitudinal studies are needed to address this shortcoming.

\section{Conclusions}

Several factors associated with recent HIV testing among high-risk MSM in this study have been identified. The factors included exposure to HIV education, perception of high HIV risk, STI diagnosis, and condom use during sexual intercourse with both men and women and in anal intercourse with boyfriends. In Cambodia, significant efforts have been made to implement structural interventions with service packages for MSM. HIV education and social marketing should be expanded and specifically designed for MSM, addressing the increased risk of unprotected anal sexual intercourse and the importance of regular HIV testing for early enrolment in the care and treatment cascade.

\section{Competing interests}

The authors declare that they have no competing interests.

\section{Authors' contributions \\ SY managed the literature review, designed the study, developed the research protocol, analyzed the data, and prepared the manuscript. ST and PC were responsible for data collection and entry. ST, PC, CB, KP, and SO supported the study design, protocol development, analyses of the study findings, and manuscript writing. All authors read and approved the final manuscript.}

\section{Acknowledgements \\ Data used for this analysis were collected as part of the impact evaluation of the SAHACOM funded by the United States Agency for International Development (USAID). The authors thank KHANA's Senior Management Team and the provincial health departments of Battembang and Siem Reap for their endless support. Special thanks are deserved by our research assistants, implementing partners, local authorities, community support volunteers, outreach workers as well as all the study participants for their excellent contribution to the data collection. Without such extensive supports, this study would have been impossible.}

Received: 18 March 2015 Accepted: 24 July 2015

Published online: 01 August 2015

\section{References}

1. National Center for HIV/AIDS, Dermatology, and STD (NCHADS). Annual report 2012. Phnom Penh, Cambodia: NCHADS; 2013.
2. Vun MC, Fujita M, Rathavy T, Eang MT, Sopheap S, Sovannarith S, et al. Achieving universal access and moving towards elimination of new HIV infections in Cambodia. J Int AIDS Soc. 2014;17:18905.

3. UNAIDS. Joint United Nations Program on HIV/AIDS. Cambodia takes MDG prize for excellence in its AIDS response. UNAIDS: Geneva, Switzerland; 2010.

4. Couture MC, Sansothy N, Sapphon V, Phal S, Sichan K, Stein E, et al. Young women engaged in sex work in Phnom Penh, Cambodia, have high incidence of HIV and sexually transmitted infections, and amphetamine-type stimulant use: new challenges to HIV prevention and risk. Sex Transm Dis. 2011;38(1):33-9.

5. Liu KL, Chhea C. The BROS Khmer: Behavioral risks on-site serosurvey among at-risk urban men in Cambodia. Phnom Penh, Cambodia: FHI 360; 2010.

6. Grulich AE, Kaldor JM. Trends in HIV incidence in homosexual men in developed countries. Sex Health. 2008;5(2):113-8.

7. Jaffe HW, Valdiserri RO, De Cock KM. The reemerging HIV/AIDS epidemic in men who have sex with men. JAMA. 2007;298(20):2412-4.

8. Likatavicius G, Klavs I, Devaux I, Alix J, Nardone A. An increase in newly diagnosed HIV cases reported among men who have sex with men in Europe, 2000-6: implications for a European public health strategy. Sex Transm Infect. 2008;84(6):499-505.

9. Cáceres CF, Konda K, Segura ER, Lyerla R. Epidemiology of male same-sex behaviour and associated sexual health indicators in low- and middle-income countries: 2003-2007 estimates. Sex Transm Infect. 2008;84 Suppl 1:i49-56.

10. de Lind van Wijngaarden JW, Brown T, Girault P, Sarkar S, van Griensven F. The epidemiology of human immunodeficiency virus infection, sexually transmitted infections, and associated risk behaviors among men who have sex with men in the Mekong Subregion and China: implications for policy and programming. Sex Transm Dis. 2009;36(5):319-24.

11. van Griensven F. Men who have sex with men and their HIV epidemics in Africa. AIDS. 2007;21(10):1361-2.

12. van Griensven F, de Lind van Wijngaarden JW, Baral S, Grulich A. The global epidemic of HIV infection among men who have sex with men. Curr Opin HIV AIDS. 2009;4(4):300-7.

13. Baral S, Sifakis F, Cleghorn F, Beyrer C. Elevated risk for HIV infection among men who have sex with men in low- and middle-income countries 2000-2006: a systematic review. PLoS Med. 2007;4(12), e339.

14. Beyrer C, Baral S, Walker D, Wirtz A, Johns B, Sifakis F. The expanding epidemics of HIV-1 among men who have sex with men in low and middle income countries: diversity and consistency. Epidemiol Rev. 2010;32(1):137-51.

15. Beyrer C, Baral SD, van Griensven F, Goodreau SM, Chariyalertsak S, Wirtz AL, et al. Global epidemiology of HIV infection in men who have sex with men. Lancet. 2012;380(9839):367-77.

16. Beyrer C, Sullivan P, Sanchez J, Baral SD, Collins C, Wirtz AL, et al. The increase in global HIV epidemics in MSM. AIDS. 2013;27(17):2665-78.

17. Oldenburg CE, Perez-Brumer AG, Reisner SL, Mimiaga MJ. Transactional sex and the HIV epidemic among men who have sex with men (MSM): Results from a systematic review and meta-analysis. AIDS Behav. 2015. (In press).

18. Beyrer C, Wirtz A, Walker D, Johns B, Sifakis F, Baral S. The global HIV epidemics among men who have sex with men. Washington, DC: The World Bank; 2011.

19. Blas MM, Alva IE, Cabello R, Carcamo C, Kurth AE. Risk behaviors and reasons for not getting tested for HIV among men who have sex with men: an online survey in Peru. PLoS One. 2011;6(11), e27334.

20. Gu J, Lau JT, Wang Z, Wu AM, Tan X. Perceived Empathy of Service Providers Mediates the Association between Perceived Discrimination and Behavioral Intention to Take Up HIV Antibody Testing Again among Men Who Have Sex with Men. PLoS One. 2015;10(2), e0117376.

21. Lau JT, Gu J, Tsui HY, Wang Z. Prevalence and associated factors of intention to participate in HIV voluntary counseling and testing for the first time among men who have sex with men in Hong Kong, China. Prev Med. 2013;57(6):813-8.

22. Li X, Wu G, Lu R, Feng L, Fan W, Xiao Y, et al. HIV-testing behavior and associated factors among MSM in Chongqing, China: results of 2 consecutive cross-sectional surveys from 2009 to 2010. Medicine. 2014;93(27), e124.

23. Mikolajczak J, Hospers HJ, Kok G. Reasons for not taking an HIV-test among untested men who have sex with men: An internet study. AIDS Behav. 2006;10(4):431-5.

24. Park JN, Papworth E, Billong SC, Elat JB, Kassegne S, Grosso A, et al. Correlates of prior HIV testing among men who have sex with men in Cameroon: a cross-sectional analysis. BMC Public Health. 2014;14:1220. 
25. Vutthikraivit $P$, Lertnimitr $B$, Chalardsakul $P$, Imjaijitt $W$, Piyaraj $P$. Prevalence of HIV Testing and Associated Factors among Young Men Who Have Sex with Men (MSM) in Bangkok, Thailand. J Med Assoc Thai. 2014;97 suppl 2:S207-13.

26. Zhang L, Xiao Y, Lu R, Wu G, Ding X, Qian HZ, et al. Predictors of HIV testing among men who have sex with men in a large Chinese city. Sex Transm Dis. 2013;40(3):235-40.

27. National Center for HIV/AIDS, Dermatology, and STD (NCHADS). Behavioral Sentinel Surveillance (BSS, 2013). Phnom Penh, Cambodia: NCHADS; 2013.

28. Thompson MA, Aberg JA, Cahn P, Montaner JS, Rizzardini G, Telenti A, et al. Antiretroviral treatment of adult HIV infection: 2010 recommendations of the International AIDS Society-USA panel. JAMA. 2010;304(3):321-33.

29. Brick N. Voluntary counseling and testing (VCT) for changing HIV-related risk behavior in developing countries: a Cochrane review summary. Public Health Nurs. 2013;30(4):382-4.

30. World Health Organization (WHO), UNAIDS. Guidance on providerinitiated HIV testing and counseling in health facilities. Geneva, Switzerland: WHO/UNAIDS; 2007.

31. Centers for Disease Control and Prevention. HIV testing among men who have sex with men-21 cities, United States, 2008. MMWR Morb Mortal Wkly Rep. 2011;60(21):694-9.

32. Lorenc T, Marrero-Guillamón I, Llewellyn A, Aggleton P, Cooper C, Lehmann A, et al. HIV testing among men who have sex with men (MSM): systematic review of qualitative evidence. Health Educ Res. 2011;26(5):834-46.

33. Song Y, Li X, Zhang L, Fang X, Lin X, Liu Y, et al. HIV-testing behavior among young migrant men who have sex with men (MSM) in Beijing, China. AIDS Care. 2011;23(2):179-86.

34. Nel JA, Yi H, Sandfort TG, Rich E. HIV-untested men who have sex with men in South Africa: the perception of not being at risk and fear of being tested. AIDS Behav. 2013;17 Suppl 1:S51-9.

35. Lachowsky NJ, Saxton PJ, Dickson NP, Hughes AJ, Summerlee AJ, Dewey CE. Factors associated with recent HIV testing among younger gay and bisexual men in New Zealand, 2006-2011. BMC Public Health. 2014;14:294.

36. Zhao Y, Zhang L, Zhang H, Xia D, Pan SW, Yue H, et al. HIV Testing and Preventive Services Accessibility Among Men Who Have Sex With Men at High Risk of HIV Infection in Beijing, China. Medicine. 2015;94(6), e534.

37. Yi S, Chhoun P, Brant S, Kita K, Tuot S. The Sustainable Action against HIV and AIDS in Communities (SAHACOM): Impacts on health and quality of life of people living with HIV in Cambodia. Glob J Med Public Health. 2014;3(5):1-12.

38. Yi S, Chhoun P, Brant S, Samedy S, Kouland T, Tuot S. The impact of integrating HIV and sexual reproductive health services on health and healthcare-seeking behavior of female entertainment workers in Cambodia. BMC Infect Dis. 2015;15:221.

39. Yi S, Chhoun P, Brant S, Kita K, Tuot S. Improving Education Opportunity, Health, and Quality of Life of Orphans and Vulnerable Children: The Sustainable Action against HIV and AIDS in Communities (SAHACOM). Int J Trop Dis Health. 2015:5(1):37-47.

40. Yi S, Chhoun P, Suong S, Thin K, Brody C, Tuot S. AIDS-Related Stigma and Mental Disorders among People Living with HIV: A cross-Sectional Study in Cambodia. PLoS One. 2015;10(3), e0121461.

41. Heng S, Tuot S. Mid-term review of the sustainable action against HIV and AIDS in communities (SAHACOM). KHANA: Phnom Penh, Cambodia; 2013.

42. National Institute of Public Health, National Institute of Statistics and ORC Macro. Cambodia Demographic and Health Survey 2010. Phnom Penh, Cambodia and Calverton, Maryland, USA: National Institute of Public Health, National Institute of Statistics, and ORC Macro; 2010.

43. Ministry of Education, Youth, and Sports (MEYS). Examining life experiences and HIV risks of young entertainment workers in four Cambodian cities. Phnom Penh, Cambodia: MEYS; 2012.

44. Yi S, Poudel KC, Yasuoka J, Palmer PH, Yi S, Jimba M. Role of risk and protective factors in risky sexual behavior among high school students in Cambodia. BMC Public Health. 2010;10:477.

45. Kalichman SC, Simbayi LC. HIV testing attitudes, AIDS stigma, and voluntary HIV counselling and testing in a black township in Cape Town, South Africa. Sex Transm Infect. 2003;79(6):442-7.

46. Carey MP, Schroder KE. Development and psychometric evaluation of the brief HIV Knowledge Questionnaire. AIDS Educ Prev. 2002;14(2):172-82.

47. Yi S, Chhoun P, Brody C, Tith K, Tuot S. Improving prevention and care for HIV and sexually transmitted infections among men who have sex with men in
Cambodia: The Sustainable Action against HIV and AIDS in Communities (SAHACOM). J Int AIDS Soc. 2014. (In press).

48. Reisen CA, Zea MC, Bianchi FT, Poppen PJ, del Río González AM, Romero RA, et al. HIV testing among MSM in Bogotá, Colombia: the role of structural and individual characteristics. AIDS Educ Prev. 2014;26(4):328-44.

49. Brener L, Callander D, Slavin S, de Wit J. Experiences of HIV stigma: the role of visible symptoms, HIV centrality and community attachment for people living with HIV. AIDS Care. 2013;25(9):1166-73.

50. Dowson L, Kober C, Perry N, Fisher M, Richardson D. Why some MSM present late for HIV testing: a qualitative analysis. AIDS Care. 2012;24(2):204-9.

51. Baral S, Trapence G, Motimedi F, Umar E, lipinge S, Dausab F, et al. HIV prevalence, risks for HIV infection, and human rights among men who have sex with men (MSM) in Malawi, Namibia, and Botswana. PLoS One. 2009;4(3), e4997.

52. Baral SD, Ketende S, Mnisi Z, Mabuza X, Grosso A, Sithole B, et al. A cross-sectional assessment of the burden of HIV and associated individual- and structural-level characteristics among men who have sex with men in Swaziland. J Int AIDS Soc. 2013;16 Suppl 3:18768.

\section{Submit your next manuscript to BioMed Central and take full advantage of:}

- Convenient online submission

- Thorough peer review

- No space constraints or color figure charges

- Immediate publication on acceptance

- Inclusion in PubMed, CAS, Scopus and Google Scholar

- Research which is freely available for redistribution

Submit your manuscript at www.biomedcentral.com/submit
C) Biomed Central 